\title{
Preparation of AgI/Silica/Poly(Ethylene Glycol) Nanoparticle Colloid Solution and X-Ray Imaging Using It
}

\author{
Yoshio Kobayashi, ${ }^{1}$ Tetsuya Ayame, ${ }^{1}$ Tomohiko Nakagawa, ${ }^{2}$ \\ Yohsuke Kubota, ${ }^{2}$ Kohsuke Gonda, ${ }^{2}$ and Noriaki Ohuchi ${ }^{2}$ \\ ${ }^{1}$ Department of Biomolecular Functional Engineering, College of Engineering, Ibaraki University, 4-12-1 Naka-narusawa-cho, \\ Hitachi, Ibaraki 316-8511, Japan \\ ${ }^{2}$ Division of Surgical Oncology, Graduate School of Medicine, Tohoku University, 2-1 Seiryo-machi, Aoba-ku, Sendai, \\ Miyagi 980-8574, Japan \\ Correspondence should be addressed to Yoshio Kobayashi; ykoba@mx.ibaraki.ac.jp
}

Received 20 June 2013; Accepted 10 July 2013

Academic Editors: T. Maffeis and M.-Q. Zhu

Copyright ( $) 2013$ Yoshio Kobayashi et al. This is an open access article distributed under the Creative Commons Attribution License, which permits unrestricted use, distribution, and reproduction in any medium, provided the original work is properly cited.

\begin{abstract}
This work performed X-ray imaging of mouse by using aqueous colloid solution of AgI nanoparticles coated with silica (AgI/ $\mathrm{SiO}_{2}$ ) and then surface-modified with poly(ethylene glycol) (PEG) (AgI/SiO $/ \mathrm{PEG}$ ). A colloid solution of AgI nanoparticles was prepared by mixing silver perchlorate and potassium iodide in water. The AgI nanoparticles were surface-modified with 3-mercaptopropyltrimethoxysilane and then were silica-coated by a sol-gel reaction between tetraethylorthosilicate and $\mathrm{H}_{2} \mathrm{O}$ catalyzed with $\mathrm{NaOH}$ in ethanol. The $\mathrm{AgI} / \mathrm{SiO}_{2}$ particle surface was modified with PEG by using methoxy PEG silane $\left(\mathrm{CH}_{3} \mathrm{O}\left(\mathrm{CH}_{2} \mathrm{CH}_{2} \mathrm{O}\right)_{n} \mathrm{CH}_{2} \mathrm{CONHC}_{3} \mathrm{H}_{6} \mathrm{Si}\left(\mathrm{OC}_{2} \mathrm{H}_{5}\right)_{3}\right)$. The $\mathrm{AgI} / \mathrm{SiO}_{2} / \mathrm{PEG}$ colloid solution revealed a computed tomography value as high as $1343.6 \mathrm{HU}$ at an iodine concentration of $0.1 \mathrm{M}$, which was higher than a commercial X-ray contrast agent with the same iodine concentration. Tissues of mouse could be imaged by injecting the concentrated colloid solution into them.
\end{abstract}

\section{Introduction}

$\mathrm{X}$-ray imaging is one of the quite useful techniques for medical diagnosis. Chemicals composed of iodine absorb strongly $\mathrm{X}$-ray. This property has been utilized for making X-ray images clearer, or taking high contrast images. Various iodine compounds have been thus far proposed as X-ray contrast agents [1-5], and several iodine compounds are commercially available. The iodine compounds, however, cannot be used for patients, in which adverse events as allergic reactions may be provoked by the iodine compounds [6-8]. In iodine compound nanoparticles coated with shell of materials inert for living bodies, that is, core-shell particles composed of core of iodine compound nanoparticles and shell of materials inert for living bodies, the shell prevents the iodine compound particles from contacting with living bodies. As a result, toxicity of iodine compounds will decrease.
Several researchers have extensively performed coating of nanoparticles with silica, which is inert for living bodies [9-15]. Their coating methods are based on a sol-gel process. Our research group has studied silica coating of various nanoparticles with the sol-gel process [16-26]. Our group has also proposed a method for silica coating of nanoparticles of silver iodide (AgI) that is one of the iodine compounds [2735].

The present work performed synthesis of colloid solution of silica-coated $\mathrm{AgI}$ nanoparticles $\left(\mathrm{AgI} / \mathrm{SiO}_{2}\right)$ by our proposed method. Furthermore, the $\mathrm{AgI} / \mathrm{SiO}_{2}$ nanoparticles were surface-modified with poly(ethylene glycol) (PEG) (PEGylation), which is expected to improve its imaging ability in living bodies. X-ray imaging ability of the colloid solution of the PEGylated $\mathrm{AgI} / \mathrm{SiO}_{2}\left(\mathrm{AgI} / \mathrm{SiO}_{2} / \mathrm{PEG}\right)$ nanoparticles was investigated using a mouse, into which the $\mathrm{AgI} / \mathrm{SiO}_{2} / \mathrm{PEG}$ nanoparticle colloid solution was injected. 


\section{Experimental}

2.1. Chemicals. AgI nanoparticles were prepared from $\mathrm{AgClO}_{4}$ (Kanto Chemical, 99\%) and KI (Kanto Chemical, 99.5\%). A silane coupling agent used to increase affinity between AgI particle surface and silica shell was 3-mercaptopropyltrimethoxysilane (MPS) (Sigma-Aldrich, 97\%). A silica source, a catalyst for a sol-gel reaction of TEOS, and a solvent in silica coating were tetraethylorthosilicate (TEOS) (Kanto Chemical, 95\%), $\mathrm{NaOH}$ aqueous solution (Kanto Chemical, $1 \mathrm{~mol} / \mathrm{L}$ ), and ethanol (Kanto Chemical, 99.5\%), respectively. Used for PEGylation of $\mathrm{AgI} / \mathrm{SiO}_{2}$ particle surface was methoxy $\mathrm{PEG}$ silane $\left(\mathrm{CH}_{3} \mathrm{O}\right.$ $\left.\left(\mathrm{CH}_{2} \mathrm{CH}_{2} \mathrm{O}\right)_{n} \mathrm{CH}_{2} \mathrm{CONHC}_{3} \mathrm{H}_{6} \mathrm{Si}\left(\mathrm{OC}_{2} \mathrm{H}_{5}\right)_{3}\right)$ (M-PEG-SLN) (JenKem Technology, Mw: 5000). Iopamiron 300 (Bracco Eisai, iodine concentration: $2.36 \mathrm{M}$ ), a commercial X-ray contrast agent, was used for a comparison to the $\mathrm{AgI} / \mathrm{SiO}_{2}$ particles in measurements of computed tomography (CT) values. All chemicals were used as received. Water that was ion-exchanged and distilled with Yamato WG-250 was used in all the preparation.

2.2. Preparation. An $\mathrm{AgI} / \mathrm{SiO}_{2} / \mathrm{PEG}$ particle colloid solution was prepared by a process composed of a method for producing $\mathrm{AgI} / \mathrm{SiO}_{2}$ nanoparticle colloid solution, which was reported in our previous work [32] and a method for PEGylation of the $\mathrm{AgI} / \mathrm{SiO}_{2}$ particle surface. First, the AgI particle colloid solution was prepared by adding a KI aqueous solution to $\mathrm{AgClO}_{4}$ aqueous solution under vigorous stirring at $20^{\circ} \mathrm{C}$. Concentrations of $\mathrm{AgClO}_{4}$ and $\mathrm{KI}$ in the colloid solution were $3.9 \times 10^{-4}$ and $7.8 \times 10^{-4} \mathrm{M}$, respectively; an AgI concentration in the colloid solution was $3.9 \times 10^{-4} \mathrm{M}$. Color of the solution turned yellow immediately after the addtion, which implied formation of AgI nanoparticles. Second, the AgI nanoparticles were silica-coated by performing a solgel method in the presence of the AgI nanoparticles, as follows. At $15 \mathrm{~min}$ after the preparation of AgI nanoparticle colloid solution, an MPS aqueous solution was added to the colloid solution. At $15 \mathrm{~min}$ after the addition, ethanol, TEOS, and $\mathrm{NaOH}$ aqueous solution were successively added to the colloid solution. The reaction time was $24 \mathrm{~h}$. Initial concentrations of AgI, MPS, $\mathrm{NaOH}, \mathrm{H}_{2} \mathrm{O}$, and TEOS in the final colloid solution were $1.0 \times 10^{-4}, 4.5 \times 10^{-6}, 1.2 \times$ $10^{-3}, 15$, and $4.0 \times 10^{-3} \mathrm{M}$, respectively. TEM observation performed in our previous work [32] revealed that these preparation conditions resulted in production of silica-coated particles with an average particle size of $53.2 \pm 9.3 \mathrm{~nm}$, which contained the AgI nanoparticles with an average particle size of $13.5 \pm 4.2 \mathrm{~nm}$. Third, PEGylation of $\mathrm{AgI} / \mathrm{SiO}_{2}$ particle surface was performed by using the M-PEG-SLN, or PEG with a silicone alkoxide group, since the M-PEGSLN is expected to be introduced on the $\mathrm{AgI} / \mathrm{SiO}_{2}$ particle surface through a reaction between the silanol groups on the particle surface and alkoxide groups of the M-PEG-SLN. The $\mathrm{AgI} / \mathrm{SiO}_{2}$ particle colloid solution was preconcentrated by a salting-out technique. The $\mathrm{AgI} / \mathrm{SiO}_{2}$ particles were sedimented adjusting $\mathrm{NaCl}$ concentration in the colloid solution to $10 \mathrm{~g} / \mathrm{L}$ with addition of a saturated $\mathrm{NaCl}$ aqueous

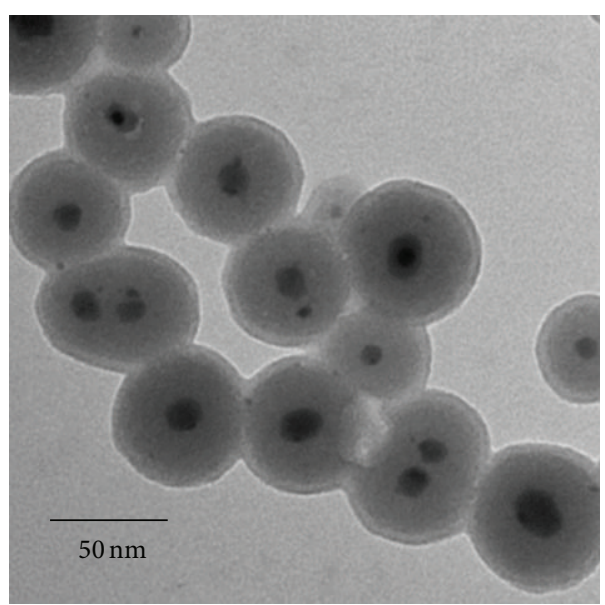

Figure 1: TEM image of $\mathrm{AgI} / \mathrm{SiO}_{2} / \mathrm{PEG}$ particles.

solution. Then, the supernatant of the colloid solution was removed by decantation. After the preconcentration by the saltingout, the $\mathrm{AgI} / \mathrm{SiO}_{2}$ particles were washed by repeating a process composed of centrifuge, removal of supernatant with decantation, addition of the water, and shaking with a vortex mixer three times. The particle colloid solution was concentrated up to an AgI concentration above $0.1 \mathrm{M}$ by decreasing the amount of added water in the washing process. For PEGylation of particle surface, or producing AgI/SiO $/ 2$ PEG particles, an M-PEG-SLN aqueous solution was added to the concentrated particle colloid solution, in which concentrations of AgI and M-PEG-SLN were 0.1 and $1.0 \times 10^{-3} \mathrm{M}$, respectively.

2.3. Characterization. The particles were observed by a JEOL JEM-2000FX II transmittance electron microscope (TEM) operating at $200 \mathrm{kV}$. Samples for TEM were prepared by dropping and evaporating the nanoparticle suspensions on a collodion-coated copper grid. X-ray images and CT values of samples such as Iopamiron 300, the $\mathrm{AgI} / \mathrm{SiO}_{2} / \mathrm{PEG}$ particle colloid solutions, and an ICR mouse were obtained with an Aloka La theta LCT-200 CT system, according to our previous work [32]. The samples were put into a tube with a diameter of $3.7 \mathrm{~cm}$ and a length of $29.5 \mathrm{~cm}$, and then their images were taken as if the samples were cut into round slices. The CT values were estimated on the basis of CT values of -1000 for air and 0 for water. The ICR mouse used was 56 weeks old. The mouse was put under anesthesia, and the colloid solutions $(0.1 \mathrm{~mL})$ were injected into the mouse from its tail veins.

\section{Results and Discussion}

3.1. AgI/SiO ${ }_{2} / P E G$ Particles. Figure 1 shows a TEM image of the $\mathrm{AgI} / \mathrm{SiO}_{2} / \mathrm{PEG}$ particles. The core-shell structure was reserved even after the PEGylation. The $\mathrm{AgI} / \mathrm{SiO}_{2} / \mathrm{PEG}$ particle size and the AgI core size were $55.7 \pm 8.6$ and $16.1 \pm$ $3.9 \mathrm{~nm}$, respectively, which were almost the same as those 


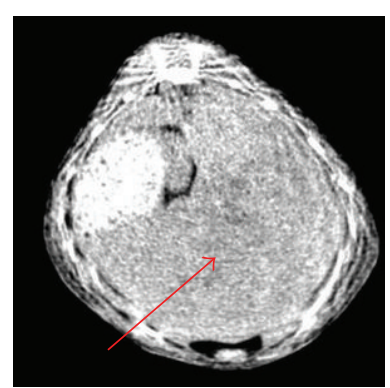

(a)

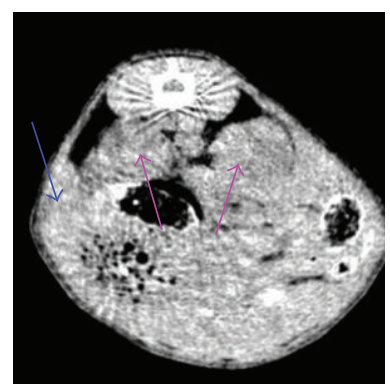

(a)

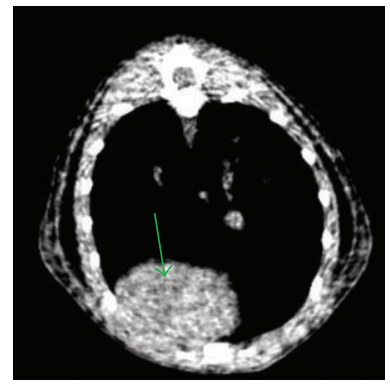

(a)

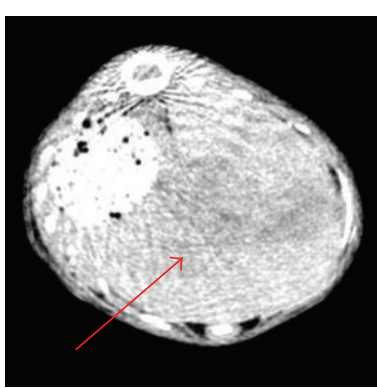

(b)

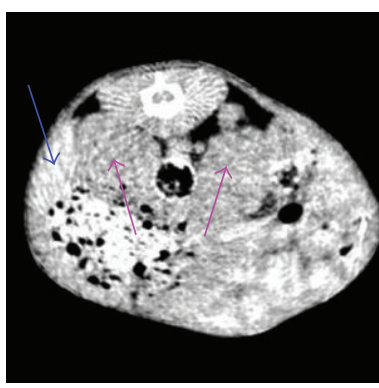

(b)

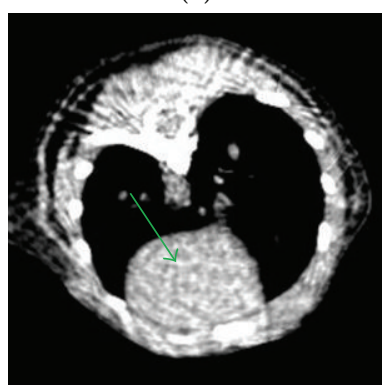

(b)

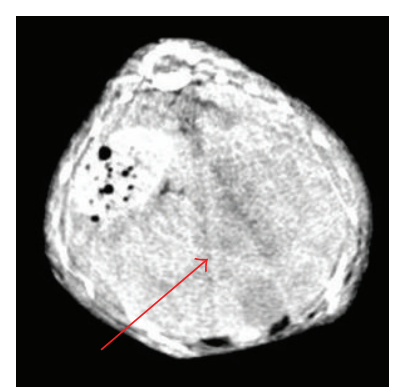

(c)

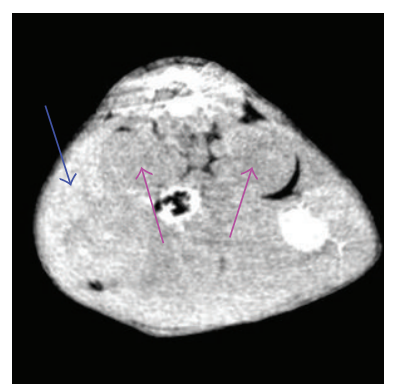

(c)

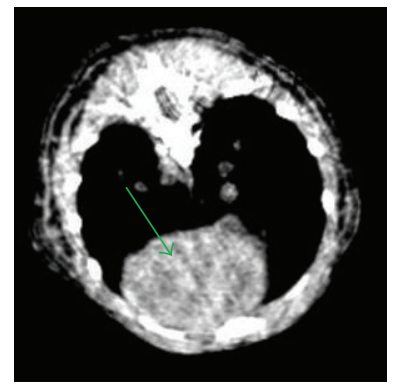

(c)

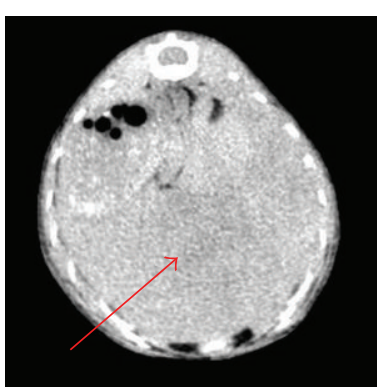

(d)

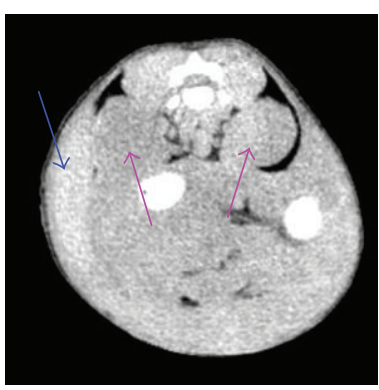

(d)

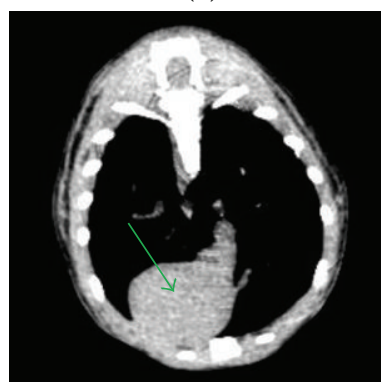

(d)

Figure 2: CT images of liver (red arrows), spleen (blue arrows), kidney (pink arrows), and heart (green arrows) of mouse after injection of $\mathrm{AgI} / \mathrm{SiO}_{2} / \mathrm{PEG}$ particle colloid solution. The images were taken (a) prior to injection, at (b) 5, (c) 1440, and (d) 2880 min after injection.

prior to the PEGylation. This indicated that the $\mathrm{AgI} / \mathrm{SiO}_{2}$ particle structure was preserved even after the PEGylation.

A CT value of the $\mathrm{AgI} / \mathrm{SiO}_{2} / \mathrm{PEG}$ particle colloid solution with the iodine concentration of $0.1 \mathrm{M}$ was $1343.6 \mathrm{HU}$, in which the AgI concentration in the particle colloid solution $(0.1 \mathrm{M})$ was regarded as the iodine concentration. Accordingly, the CT value with respect to the iodine concentration was $1.34 \times 10^{5} \mathrm{HU} / \mathrm{M}$. For Iopamiron 300 , our previous work gave that a CT value of Iopamiron 300 was $333.8 \mathrm{HU}$ at an iodine concentration adjusted to $0.073 \mathrm{M}$ [25]; the CT value with respect to the iodine concentration was $4.57 \times 10^{3} \mathrm{HU} / \mathrm{M}$. These measurements indicated that the $\mathrm{CT}$ value of the $\mathrm{AgI} / \mathrm{SiO}_{2} / \mathrm{PEG}$ particle colloid solution was approximately three times larger than that of Iopamiron 300; the $\mathrm{AgI} / \mathrm{SiO}_{2} / \mathrm{PEG}$ particle colloid solution could function as an X-ray contrast agent sensitive compared to Iopamiron 300.

Two possible mechanisms on the large CT value for the $\mathrm{AgI} / \mathrm{SiO}_{2} / \mathrm{PEG}$ particle colloid solution were considered as follows. The first possible mechanism was based on adsorption of excess $\mathrm{I}^{-}$. For stabilizing the AgI particles colloidally thorough adsorption of $\mathrm{I}^{-}$ions on AgI particle surface [36], $\mathrm{KI}$ was excessively added to the $\mathrm{AgClO}_{4}$ solution for the preparation of AgI particle colloid solution. Some of the excess $\mathrm{I}^{-}$were probably left on the AgI nanoparticles through the adsorption, which made an actual iodine concentration larger than the AgI concentration of $0.1 \mathrm{M}$. The second possible mechanism was based on X-ray absorption ability of silver. The AgI nanoparticles are composed of both silver and iodine. Silver also absorbs X-ray strongly because of its large atomic number. Consequently, it was concluded that the two possible mechanisms explained that the $\mathrm{AgI} / \mathrm{SiO}_{2} / \mathrm{PEG}$ particle colloid solution revealed a CT value larger than expected.

3.2. X-Ray Imaging of Mouse. Figure 2 shows X-ray images of the mouse prior to and after the injection of the $\mathrm{AgI} / \mathrm{SiO}_{2} / \mathrm{PEG}$ particle colloid solution. Prior to the injection, tissues such as liver and spleen in the images were hard to be recognized because of small differences in contrast between them and other parts. Just after the injection ( $5 \mathrm{~min}$ ), these tissues were imaged, since contrasts of these tissues became lighter than prior to the injection. Kidney and heart were easy to be recognized even prior to the injection, judging from their expected shapes and locations in body. Just after the injection, these tissues were imaged, though the images 


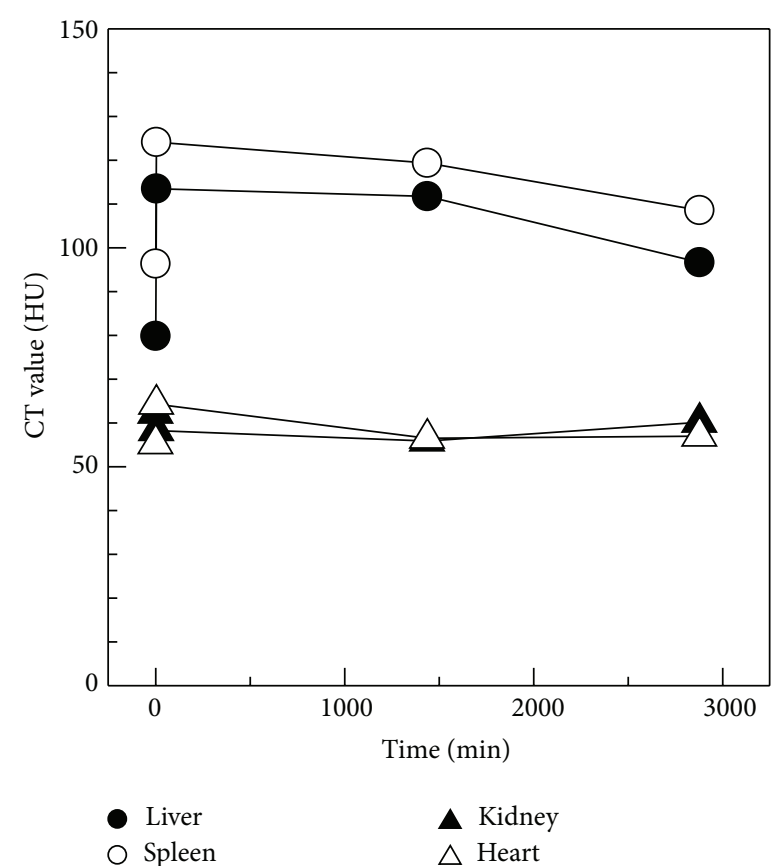

FIGURE 3: CT values of liver $(\bullet)$, spleen $(\circ)$, kidney $(\mathbf{\Delta})$, and heart $(\Delta)$ of mouse after injection of $\mathrm{AgI} / \mathrm{SiO}_{2} / \mathrm{PEG}$ particle colloid solution.

were not so clear as those of the liver and the spleen. This observation indicated that the $\mathrm{AgI} / \mathrm{SiO}_{2} / \mathrm{PEG}$ particles flew in blood tubes, reached the tissues, and then were probably recognized as alien substances and were intensively trapped in them. Over $5 \mathrm{~min}$, the contrasts of liver and spleen tended to become darker with an increase in time.

Figure 3 shows dependencies of CT values of various tissues on time after the injection. The CT values of liver and spleen jumped from 79.9 to 113.5 and from 96.3 to 124.1 HU after the injection, respectively. Though the CT values of kidney and heart also jumped after the injection, their jumps were slight compared to those of liver and spleen. This supported the intensive trapping in liver and spleen. After the jumps, the values in liver and spleen decreased gradually with the increase in time. These decreases indicated that the $\mathrm{AgI} / \mathrm{SiO}_{2} / \mathrm{PEG}$ particles were metabolized and then were released from the liver and the spleen.

\section{Conclusions}

The colloid solution of $\mathrm{AgI} / \mathrm{SiO}_{2} / \mathrm{PEG}$ particle with the average size of $55.7 \pm 8.6 \mathrm{~nm}$ and the AgI core size of $16.1 \pm 3.9 \mathrm{~nm}$ was produced through PEGylation using M-PEG-SLN for the $\mathrm{AgI} / \mathrm{SiO}_{2}$ particles that were fabricated in our previous work. Its CT value was as high as $1343.6 \mathrm{HU}$ at the iodine concentration of $0.1 \mathrm{M}$, which was three times larger than that for the commercial X-ray contrast agent with the same iodine concentration. This indicated that the $\mathrm{AgI} / \mathrm{SiO}_{2} / \mathrm{PEG}$ particle colloid solution was sensitive for absorption of Xray. The injection of the colloid solution into a mouse made the X-ray images of its tissues be taken clearly. From the aforementioned experimental results, it was found that the
$\mathrm{AgI} / \mathrm{SiO}_{2} / \mathrm{PEG}$ particle colloid solutions could work as an $\mathrm{X}$-ray contrast agent. Further studies are in progress toward practical use.

\section{Conflict of Interests}

The Iopamiron 300, the MPS, the M-PEG-SLN, and the other chemicals were supplied by Bracco Eisai, Sigma-Aldrich, JenKem Technology, and Kanto Chemical, respectively, with no financial support from the four companies.

\section{Acknowledgments}

The authors express their thanks to Professor T. Noguchi in College of Science of Ibaraki University, Japan, for his help with TEM observation.

\section{References}

[1] A. de Vries, E. Custers, J. Lub, S. van den Bosch, K. Nicolay, and H. Grüll, "Block-copolymer-stabilized iodinated emulsions for use as CT contrast agents," Biomaterials, vol. 31, no. 25, pp. 65376544, 2010.

[2] D. G. Wynn, G. Humphries, V. Morisson-Iveson et al., “The synthesis and evaluation of unsymmetrical dimeric X-ray contrast agents," Tetrahedron Letters, vol. 52, no. 24, pp. 3068-3071, 2011.

[3] P. N. Bansal, R. C. Stewart, V. Entezari, B. D. Snyder, and M. W. Grinstaff, "Contrast agent electrostatic attraction rather than repulsion to glycosaminoglycans affords a greater contrast uptake ratio and improved quantitative CT imaging in cartilage," Osteoarthritis and Cartilage, vol. 19, no. 8, pp. 970-976, 2011.

[4] R. Mizutani and Y. Suzuki, "X-ray microtomography in biology," Micron, vol. 43, no. 2-3, pp. 104-115, 2012.

[5] X. Li, N. Anton, G. Zuber et al., "Iodinated $\alpha$-tocopherol nanoemulsions as non-toxic contrast agents for preclinical X-ray imaging," Biomaterials, vol. 34, no. 2, pp. 481-491, 2013.

[6] P. Bickham and J. Golembiewski, "Contrast media use in the operating room," Journal of Perianesthesia Nursing, vol. 25, no. 2, pp. 94-103, 2010.

[7] H. S. Thomsen, "Contrast media safety-an update," European Journal of Radiology, vol. 80, no. 1, pp. 77-82, 2011.

[8] S. A. Saghir, B. L. Yano, C. L. Zablotny, K. A. Brzak, A. J. Clark, and J. L. Staley, "Role of iodine in the toxicity of diiodomethyl-ptolylsulfone (DIMPTS) in rats: ADME," Regulatory Toxicology and Pharmacology, vol. 62, no. 3, pp. 482-495, 2012.

[9] Y. Li, Z. Jin, T. Li, and Z. Xiu, "One-step synthesis and characterization of core-shell $\mathrm{Fe} @ \mathrm{SiO}_{2}$ nanocomposite for $\mathrm{Cr}$ (VI) reduction," Science of the Total Environment, vol. 421-422, pp. 260-266, 2012.

[10] Z. Wu, J. Liang, X. Ji, and W. Yang, "Preparation of uniform $\mathrm{Au} @ \mathrm{SiO}_{2}$ particles by direct silica coating on citrate-capped $\mathrm{Au}$ nanoparticles," Colloids and Surfaces A, vol. 392, no. 1, pp. 220 224, 2011.

[11] L. Caruana, A. L. Costa, M. C. Cassani, E. Rampazzo, L. Prodi, and N. Zaccheroni, "Tailored $\mathrm{SiO}_{2}$-based coatings for dye doped superparamagnetic nanocomposites," Colloids and Surfaces A, vol. 410, pp. 111-118, 2012.

[12] N. M. Bahadur, T. Furusawa, M. Sato, F. Kurayama, I. A. Siddiquey, and N. Suzuki, "Fast and facile synthesis of silica 
coated silver nanoparticles by microwave irradiation," Journal of Colloid and Interface Science, vol. 355, no. 2, pp. 312-320, 2011.

[13] T. Ke, Y. Le, J. X. Wang, G. W. Chu, J. F. Chen, and L. Shao, " $\mathrm{Cu}$ nanoparticle preparation in a tube-in-tube microchannel reactor and encapsulation by silica," Materials Letters, vol. 64, no. 15, pp. 1717-1719, 2010.

[14] A. Kunzmann, B. Andersson, C. Vogt et al., "Efficient internalization of silica-coated iron oxide nanoparticles of different sizes by primary human macrophages and dendritic cells," Toxicology and Applied Pharmacology, vol. 253, no. 2, pp. 81-93, 2011.

[15] S. Wang, C. Li, P. Yang, M. Ando, and N. Murase, "Silica encapsulation of highly luminescent hydrophobic quantum dots by two-step microemulsion method," Colloids and Surfaces A, vol. 395, pp. 24-31, 2012.

[16] Y. Kobayashi, T. Nozawa, M. Takeda, N. Ohuchi, and A. Kasuya, "Direct silica-coating of quantum dots," Journal of Chemical Engineering of Japan, vol. 43, no. 6, pp. 490-493, 2010.

[17] Y. Kobayashi, T. Nozawa, T. Nakagawa et al., "Direct coating of quantum dots with silica shell," Journal of Sol-Gel Science and Technology, vol. 55, no. 1, pp. 79-85, 2010.

[18] L. Cong, M. Takeda, Y. Hamanaka et al., "Uniform silica coated fluorescent nanoparticles: synthetic method, improved light stability and application to visualize lymph network tracer," PLoS ONE, vol. 5, no. 10, Article ID e13167, 2010.

[19] Y. Kobayashi, H. Inose, T. Nakagawa et al., "Control of shell thickness in silica-coating of Au nanoparticles and their X-ray imaging properties," Journal of Colloid and Interface Science, vol. 358, no. 2, pp. 329-333, 2011.

[20] H. Morimoto, M. Minato, T. Nakagawa et al., "X-ray imaging of newly-developed gadolinium compound/silica core-shell particles," Journal of Sol-Gel Science and Technology, vol. 59, no. 3, pp. 650-657, 2011.

[21] N. M. Bahadur, S. Watanabe, T. Furusawa et al., "Rapid one-step synthesis, characterization and functionalization of silica coated gold nanoparticles," Colloids and Surfaces A, vol. 392, no. 1, pp. 137-144, 2011.

[22] Y. Kobayashi, T. Nozawa, T. Nakagawa, K. Gonda, M. Takeda, and N. Ohuchi, "Fabrication and fluorescence properties of multilayered core-shell particles composed of quantum dot, gadolinium compound, and silica," Journal of Materials Science, vol. 47, no. 4, pp. 1852-1859, 2012.

[23] Y. Kobayashi, H. Inose, T. Nakagawa et al., "Synthesis of Ausilica core-shell particles by sol-gel process," Surface Engineering, vol. 28, no. 2, pp. 129-133, 2012.

[24] Y. Kobayashi, H. Matsudo, T. Nakagawa et al., "In-vivo fluorescence imaging technique using colloid solution of multiple quantum dots/silica/poly(ethylene glycol) nanoparticles," Journal of Sol-Gel Science and Technology, vol. 66, pp. 31-37, 2012.

[25] Y. Kobayashi, H. Inose, R. Nagasu et al., "X-ray imaging technique using colloid solution of Au/silica/poly(ethylene glycol) nanoparticles," Materials Research Innovations, 2013.

[26] Y. Kobayashi, H. Inose, T. Nakagawa, Y. Kubota, K. Gonda, and N. Ohuchi, "Fabrication of multilayered Au/silica/gadolinium compound/silica core-shell particles," Materials Focus, vol. 2, no. 5, pp. 369-373, 2013.

[27] Y. Kobayashi, K. Misawa, M. Takeda et al., "Silica-coating of AgI semiconductor nanoparticles," Colloids and Surfaces A, vol. 251, no. 1-3, pp. 197-201, 2004.

[28] Y. Kobayashi, K. Misawa, M. Takeda, N. Ohuchi, A. Kasuya, and M. Konno, "Control of shell thickness in silica-coating of Agl nanoparticles," Advanced Materials Research, vol. 29-30, pp. 191194, 2007.

[29] Y. Kobayashi, K. Misawa, M. Takeda, N. Ohuchi, A. Kasuya, and M. Konno, "Preparation and properties of silica-coated AgI nanoparticles with a modified Stöber method," MRS Proceedings, vol. 1074, 2008.

[30] Y. Kobayashi, N. Shimizu, K. Misawa et al., "Preparation of amine free silica-coated Agl nanoparticles with modified Stöber method," Surface Engineering, vol. 24, no. 4, pp. 248-252, 2008.

[31] Y. Kobayashi, M. Minato, K. Ihara et al., "Synthesis of silicacoated agi nanoparticles and immobilization of proteins on them," Journal of Nanoscience and Nanotechnology, vol. 10, no. 11, pp. 7758-7761, 2010.

[32] T. Ayame, Y. Kobayashi, T. Nakagawa, K. Gonda, M. Takeda, and N. Ohuchi, "Preparation of silica-coated AgI nanoparticles by an amine-free process and their X-ray imaging properties," Journal of the Ceramic Society of Japan, vol. 119, no. 1390, pp. 397-401, 2011.

[33] Y. Kobayashi, M. Minato, K. Ihara et al., "Synthesis of high concentration colloid solution of silica-coated AgI nanoparticles," Journal For Nanoscience and Nanotechnology, vol. 12, no. 8, pp. 6741-6745, 2012.

[34] Y. Kobayashi, T. Ayame, T. Nakagawa, K. Gonda, and N. Ohuchi, "X-ray imaging technique using colloid solution of AgI/silica/poly(ethylene glycol) nanoparticles," Materials Focus, vol. 1, no. 2, pp. 127-130, 2012.

[35] Y. Sakurai, H. Tada, K. Gonda et al., "Development of silicacoated silver iodide nanoparticles and their biodistribution," The Tohoku Journal of Experimental Medicine, vol. 228, no. 4, pp. 317-323, 2012.

[36] H. Freundlich, Colloid \& Capillary Chemistry, Methuen, London, UK, 1926. 

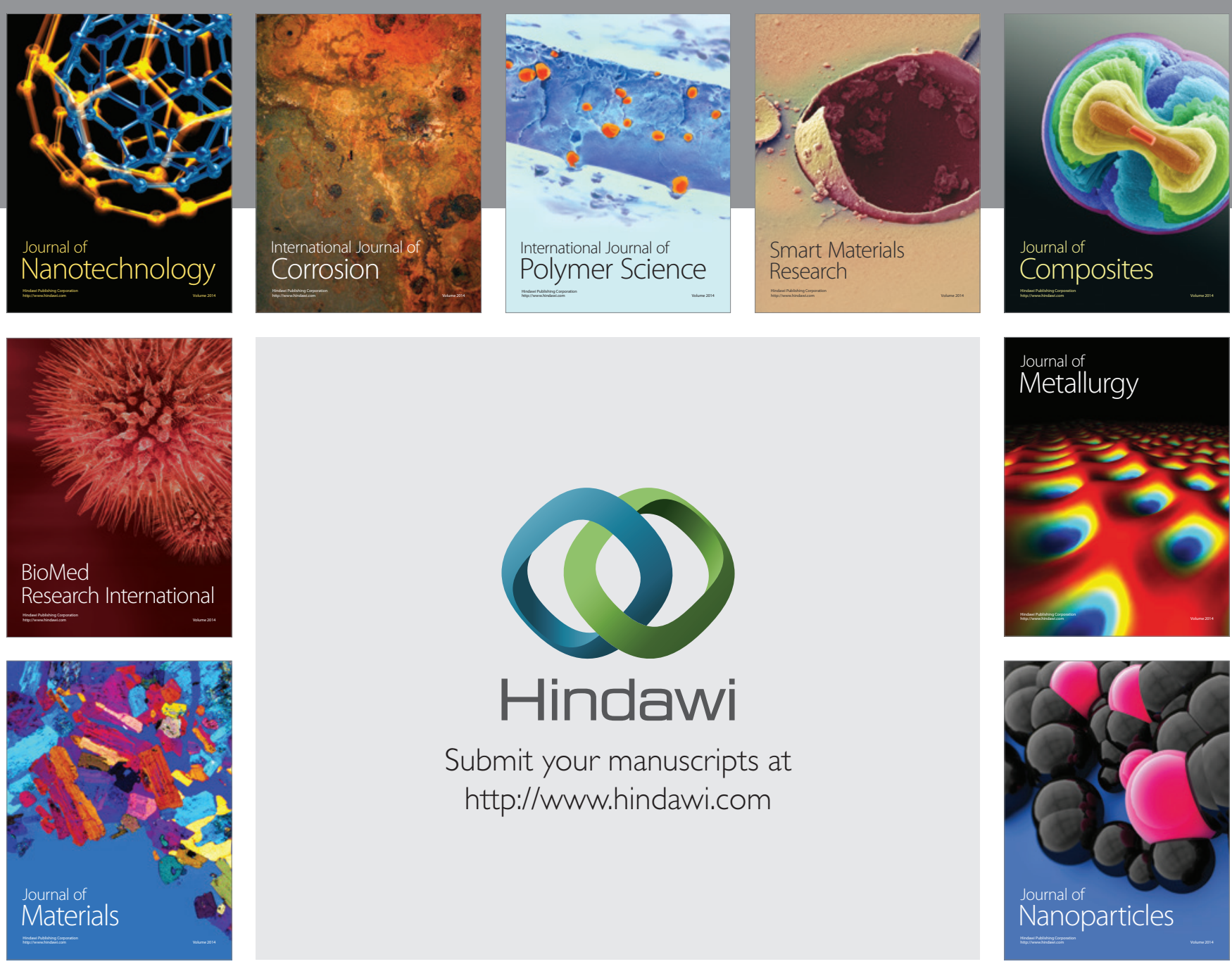

Submit your manuscripts at http://www.hindawi.com
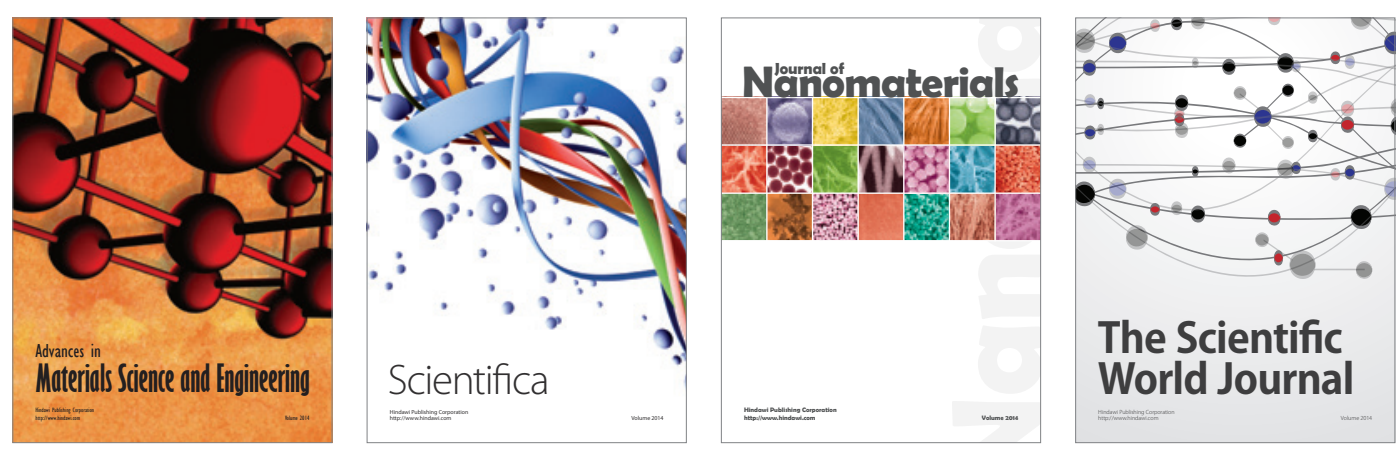

\section{The Scientific World Journal}
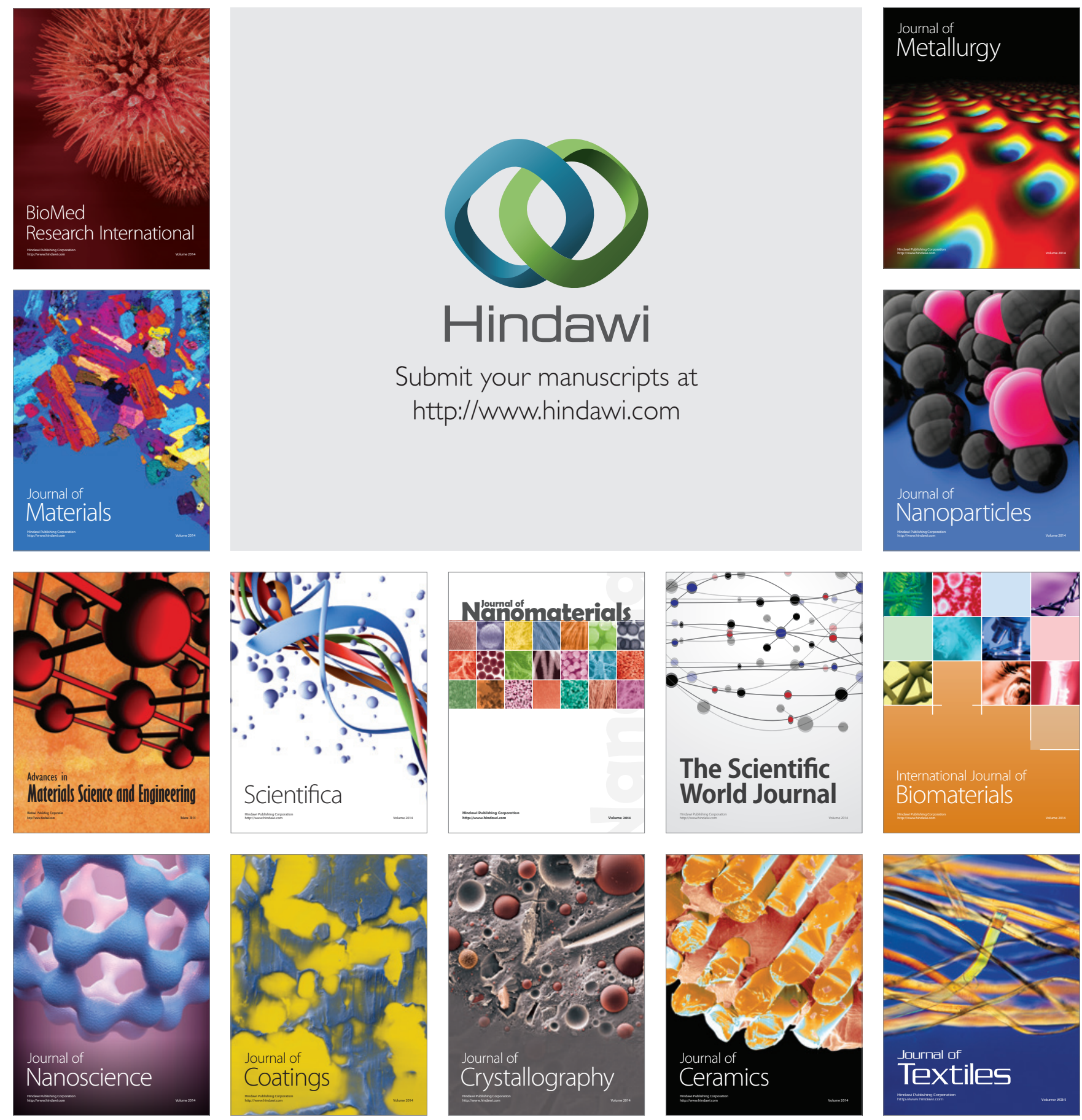